\title{
Evidence for lactate production by human adipose tissue in vivo
}

\author{
P.-A.Jansson, U. Smith and P.Lönnroth \\ Department of Medicine II, University of Gothenburg, Sahlgren's Hospital, Gothenburg, Sweden
}

\begin{abstract}
Summary. Microdialysis of the abdominal subcutaneous tissue was performed in seven healthy normal weight subjects after an overnight fast and also after oral ingestion of $100 \mathrm{~g}$ glucose. The lactate concentration in the interstitial water was compared with that in the venous and arterialized plasma from the cubital veins. In the postabsorptive state the lactate concentration in the subcutaneous tissue $(1128 \pm 72 \mu \mathrm{mol} / \mathrm{l}$, mean \pm SEM) was significantly higher $(p<0.01)$ than that in both arterialized $(722 \pm 72 \mu \mathrm{mol} / \mathrm{l})$ and venous plasma $(798 \pm 41 \mu \mathrm{mol} / \mathrm{l})$. The oral glucose load further increased the lactate level in the subcutaneous tissue throughout the observation period of $2 \mathrm{~h}$. The kinetics for the increase in the lac-
\end{abstract}

tate concentration was not apparently different in blood or tissue. The highest lactate levels were $1798 \pm 173 \mu \mathrm{mol} / 1$ in the subcutaneous tissue and $1199 \pm 150 \mu \mathrm{mol} / \mathrm{l}$ and $1275 \pm 123 \mu \mathrm{mol} / 1$ in arterialized and venous plasma, respectively. It is concluded that abdominal adipose tissue produces lactate both in the fasting state and after an oral glucose load. The data emphasize the importance of the adipose tissue as a significant source of lactate production in the body.

Key words: Adipose tissue, lactate, glucose metabolism, microdialysis.
Lactate is currently thought to be produced mainly in skeletal muscle, the splanchnic area, erythrocytes, brain and skin [1]. However, several recent in vitro studies have shown that adipocytes from both rodents and man [2,3] are capable of producing significant amounts of lactate. In fact, lactate production greatly exceeds the sum of glucose converted to both triglycerides and carbon dioxide [3].

Adipose tissue is currently considered to be of minor importance for the total body glucose homeostasis. However, since lactate production from glucose has been completely disregarded, the total amount of glucose taken up by the adipose tissue may have been underestimated [3]. If significant amounts of lactate are formed in vivo, the adipose tissue may not only be of importance for total glucose disposal but also for glucose formation by virtue of the importance of lactate as a gluconeogenic precursor in the liver.

In two recent studies in man the lactate concentration measured in blood from an epigastric vein was found to be higher than that in arterialized blood indicating a low rate of lactate production by the abdominal subcutaneous tissue $[4,5]$. However, more precise information on the possible lactate production by the adipose tissue could be obtained by measuring the lactate concentration directly in the interstitial water. Recently, we described a microdialysis technique enabling the sampling and characterization of the interstitial water of the subcutaneous adipose tissue in man [6]. By using our newly developed calibration procedure the concentration of any small molecular compound can be estimated [6]. Using this procedure we have shown that the glycerol levels are higher in the adipose tissue than in the blood while the adenosine levels are similar [7]. These findings, combined with the fact that the concentration of small molecular compounds in the tissue can be decreased (drained) by the catheters if appropriate caution is not taken, prove that microdialysis enables studies of the tissue water space [7].

In this study we have used the microdialysis technique to further explore the possibility that lactate is produced by the adipose tissue in vivo in man.

\section{Subjects and methods}

\section{Subjects}

Four healthy male and three healthy female subjects who were not on any medication and who had stable body weight for at least three months prior to the study, were recruited. Their body mass 


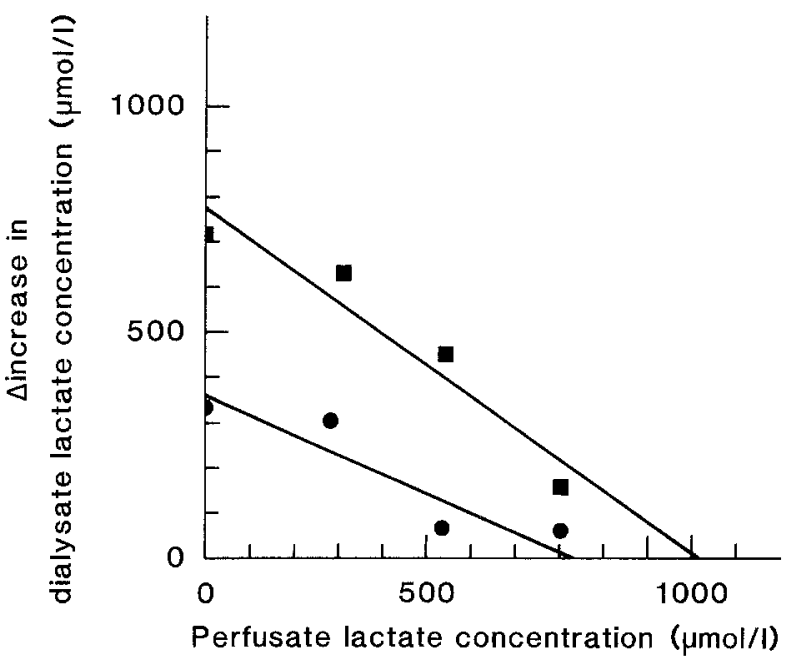

Fig.1. The importance of glucose for lactate production in adipose tissue. Two microdialysis catheters were placed in the abdominal subcutaneous tissue. One catheter was perfused with $0.9 \% \mathrm{NaCl}$ - - ) and the other with $0.9 \% \mathrm{NaCl}$ plus $2.5 \mathrm{mmol} / \mathrm{l}$ glucose (-) The figure depicts a calibration experiment where lactate concentration in the perfusate resulting in no increase in lactate concentration in the dialysate was calculated by regression analysis

index (BMI) was $22.9 \pm 0.3 \mathrm{~kg} / \mathrm{m}^{2}$ (mean $\pm \mathrm{SEM}$ ) and their age $25.6 \pm 1.8$ years. All subjects gave their informed consent and the study was approved by the Ethical Committee of the University of Gothenburg.

\section{Experimental protocol}

The investigations were started at 08.00 hours after an overnight fast. The subjects were studied in the supine position in a room kept at $25^{\circ} \mathrm{C}$. A polyethylene catheter was placed in a cubital vein for blood sampling. In three subjects arterialized blood was obtained from the contralateral cubital vein by heating the forearm to $40-50^{\circ} \mathrm{C}$ with two electric heating pads.

The microdialysis procedures were performed essentially as previously described [6]. Briefly, microdialysis catheters were made by glueing a single dialysis tubing $(30 \times 0.3 \mathrm{~mm}$, Cuprophan $\mathrm{B} 4 \mathrm{AH}$, $3000 \mathrm{MW}$ cut off, Cobe, Denver, Co., USA) to two nylon tubings after which the catheters were sterilized. The outlet of the catheter had a standardized length of $50 \mathrm{~mm}$. The sterilized catheters were placed in the subcutaneous tissue on each side of the umbilicus by the use of a fine cannula without anaesthesia. The inlet of the tubing was connected to a precision pump (SAGE Instruments, Boston, Mass., USA) and perfused with $0.9 \% \mathrm{NaCl}$ at a rate of $2.5 \mu \mathrm{l} / \mathrm{min}$. When indicated, $2.5 \mathrm{mmol} / \mathrm{h}$ glucose was added to the perfusate. After 30 min equilibration the dialysate was collected at $10 \mathrm{~min}$ intervals. After calibrating the microdialysis catheters (see below) the lactate levels were followed for $2 \mathrm{~h}$ after an oral ingestion of $100 \mathrm{~g}$ glucose.

\section{Calibration procedure}

The procedure by which the microdialysis catheters are calibrated in vivo was recently described in detail [6]. In the present study known different lactate concentrations $(0-750 \mu \mathrm{mol} / \mathrm{l}$ lactate $)$ were added to the perfusate and the tissue repeatedly dialysed. A linear relationship between the net increase of lactate in the dialysate and the concentration of lactate in the perfusate (lactate $_{\text {out }}-$ lactate $_{\text {in }}=$ net change) is then established. By use of regression analysis the lactate concentration not resulting in any change in lactate in the dialysate can then be calculated ( = interstitial lactate concentration). An excellent linear correlation between the lactate concentration in the perfusate and the net change in lactate concentration following dialysis $(r>0.9)$ persisted for at least $5 \mathrm{~h}$ in all catheters in the present study. It was then assumed that the calibration technique did not interfere with the local tissue lactate turnover. This was further supported by the finding that identical results were obtained with either L- or D-lactate added to the perfusate in repeated control experiments (unpublished observation). The recovery of the lactate concentration in the interstitial water was $51 \pm 5 \%$ (mean $\pm S E M$, $n=13)$.

\section{Statistical analysis}

Significance of differences between lactate levels in plasma and interstitial water was tested by the two-tailed Student's $t$-test for paired data. Linear regression analyses were performed according to the least squares method.

\section{Results}

Recently, we showed that erroneous results might be produced if the experiments are done under conditions where the substance under study is drained from the tissue by the microdialysis catheter [6]. Since local concentration gradients of glucose may be produced if glucose $(2.5 \mathrm{mmol} / \mathrm{l})$ is not added to the perfusate during the tissue dialysis [6] this might have an impact on the lactate production from glucose in the tissue surrounding the microdialysis catheter. To explore this possibility we conducted control experiments where one catheter was perfused with $0.9 \%$ $\mathrm{NaCl}$ plus $2.5 \mathrm{mmol} / \mathrm{l}$ glucose and another catheter, placed on the other side of the umbilicus, was perfused with only $0.9 \% \mathrm{NaCl}$.

Figure 1 depicts the data from such a calibration study in which a considerably lower lactate concentration was recorded in the catheter not perfused with glucose $(830 \mu \mathrm{mol} / 1)$. It should be noted that the lactate concentration in venous plasma was $820 \mu \mathrm{mol} / 1$ in that experiment, whereas the microdialysis catheter perfused with a low glucose concentration had an estimated lactate concentration of $1120 \mu \mathrm{mol} / 1$. Thus, no lactate production was taking place in the tissue surrounding the catheter being perfused with only $0.9 \% \mathrm{NaCl}$, whereas a significant lactate production was recorded when glucose was added. As a consequence, $2.5 \mathrm{mmol} / \mathrm{l}$ glucose was added to all perfusates throughout the study.

Figure 2 shows the mean lactate concentrations in the interstitial water of the adipose tissue and in venous and arterialized plasma. Since the arterialized lactate concentration was lower than that in venous plasma in all subjects the results were considered representative and are shown in Figure 2. In the post-absorptive state the lactate concentration in the interstitial water in the subcutaneous tissue $(1128 \pm 72 \mu \mathrm{mol} / 1)$ was significantly higher $(p<0.01)$ than that in arterialized $(722 \pm 72 \mu \mathrm{mol} / 1)$ and venous plasma $(798 \pm 41 \mu \mathrm{mol} / \mathrm{l})$. Moreover, after the oral ingestion of $100 \mathrm{~g}$ glucose tissue lactate remained significantly higher than in plasma throughout the observation period. The kinetics for the change in lactate was not clearly different between blood and tissue. Peak levels 


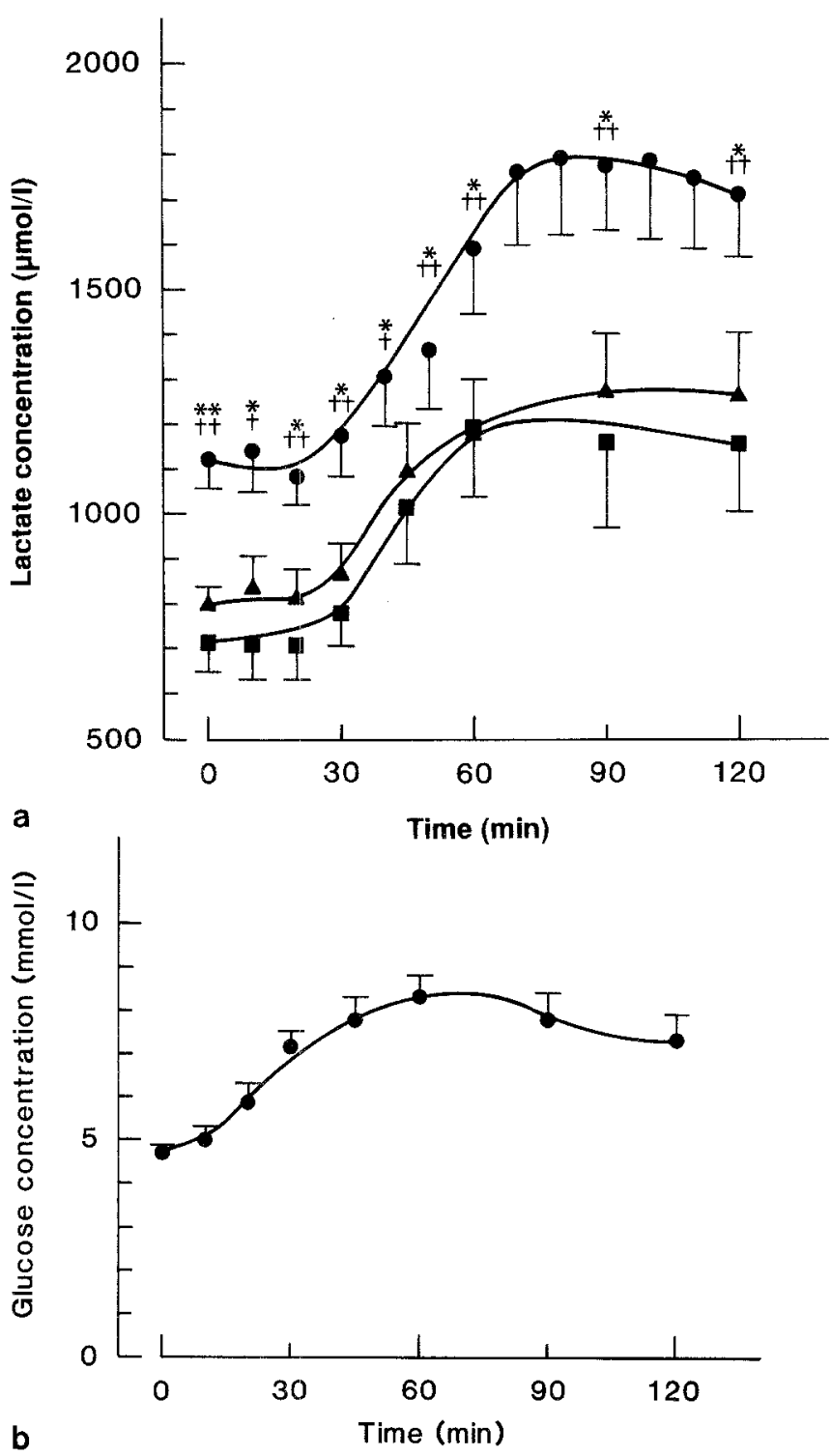

Fig.2. a Interstitial lactate concentration $(n=7)$, venous plasma $(n=7)$ and arterialized plasma levels $(n=3)$ during an oral glucose tolerance test in lean subjects. Interstitial lactate concentration $(\bullet)$; Venous plasma lactate $(₫ \mathbf{A})$; Arterialized plasma lactate $(-\mathbf{D})$. b Glucose concentration in venous plasma. Data are means \pm SEM. $* p<0.05$ and $* * p<0.01$ compared to venous lactate levels. $+p<0.05$ and $++p<0.01$ compared to arterialized lactate levels

of lactate were seen after $\sim 80 \mathrm{~min}$ in the tissue $(1798 \pm 173 \mu \mathrm{mol} / \mathrm{l})$ and after $60-90 \mathrm{~min}$ in blood $(1199 \pm 150 \mu \mathrm{mol} / \mathrm{l}$ and $1275 \pm 123 \mu \mathrm{mol} / \mathrm{l}$ in arterialized and venous plasma, respectively). The absolute increase in lactate concentration from basal to peak level was $670 \mu \mathrm{mol} / \mathrm{l}$ and $480 \mu \mathrm{mol} / \mathrm{l}$ in the subcutaneous tissue and blood, respectively.

\section{Discussion}

It was clearly shown in this study that the lactate concentration is increased in human abdominal subcutaneous tissue when compared with both arterialized and venous plasma. This difference was seen both in the post-absorptive state and following an oral glucose load. Since the catheters were placed at least $1 \mathrm{~cm}$ under the skin it is reasonable to assume that the high lactate concentration is the result of a local production within the adipose tissue. Further evidence for this was provided by the experiments showing that no increase in lactate was seen under conditions where the local glucose concentration was drained by the microdialysis catheter. Thus, it can be concluded that the ability of adipose tissue to produce lactate from glucose is not only seen in vitro $[2,3]$ but also in vivo in man.

The exact rate of lactate production in the tissue could not be calculated since the extraction fraction of lactate and the local blood flow were not measured. However, previous studies have estimated the mean blood flow in abdominal adipose tissue to $-2.5 \mathrm{ml} / 100 \mathrm{~g}$ tissue $^{-1} \cdot \min ^{-1}[8]$. Furthermore, the ready diffusion capacity for small molecules like lactate supports the view that the lactate concentration in the interstitial water is equal to that in venous blood from the same tissue area, provided that the blood flow rate is not increased dramatically [9]. Thus, although arterialized blood was not obtained in all subjects it may be speculated that the interstitial lactate concentration in the postabsorptive state corresponds to as high a production rate as $\sim 1.0 \mu \mathrm{mol}$ lactate $/ 100 \mathrm{~g}$ tissue ${ }^{-1} \cdot \mathrm{min}^{-1}$. This would be similar or even higher than the lactate production in skeletal muscle [10].

Recently, Frayn et al. [4] measured the lactate concentrations in an epigastric vein draining the skin and an unknown amount of the abdominal fat. As in the present study, no measurements of blood flow rate were made and, hence, it is difficult to draw firm quantitative conclusions. However, their data suggested that a low rate of lactate production occurs in the adipose tissue both in the postabsorptive state as well as after an oral glucose load [4, 5].

The present data do not allow us to explain the apparent difference in lactate concentration between the interstitial water and the epigastric vein $[4,5]$. Possibly, the tissue blood flow rate was exceedingly high in the study of Frayn et al. [4] and/or the blood flow shunted in the adipose tissue so that other tissues significantly contributed to the blood concentrations. Exact quantitative estimates of the adipose tissue lactate production will not be possible until the lactate concentrations in both fluid compartments are related to accurate measurements of the blood flow rate.

Since body fat was not measured in the subjects the total contribution of the adipose tissue to whole body lactate production could not be estimated. Furthermore, regional differences in adipose tissue metabolism include the capacity to produce lactate $[2,3]$ and in the present study lactate concentrations were measured only at one tissue site.

In conclusion, abdominal adipose tissue produces lactate both in the post-absorptive state as well as after an oral glucose load. These findings indicate that the adipose tissue may be of quantitative importance for total body glucose homeostasis. 
Acknowledgements. The study was supported by grants from the Swedish Medical Research Council (project number B-3506), the Swedish Diabetes Association, Socialstyrelsens Fund, Göteborgs Diabetes Association and Göteborgs Läkaresällskap.

\section{References}

1. Kreisberg RA (1972) Glucose-lactate inter-relations in man. N Engl J Med 287: 132-137

2. Newby FD, Sykes MN, DiGirolamo M (1988) Regional differences in adipocyte lactate production from glucose. Am $J$ Physiol 255: E716-E722

3. Mårin P, Rebuffé-Scrive M, Smith U, Björntorp P (1987) Glucose uptake in human adipose tissue. Metabolism 36:1154-1160

4. Frayn KN, Coppack SW, Humphreys SM, Whyte PL (1989) Metabolic characteristics of human adipose tissue in vivo. Clin Sci 76:509-516

5. Coppack SW, Frayn KN, Whyte PL, Humphreys SM (1989) Carbohydrate metabolism in human adipose tissue in vivo. Biochem Soc Transactions 17: 145-146

6. Lönnroth P, Jansson P-A, Smith U (1987) A microdialysis method allowing characterization of intercellular water space in humans. Am J Physiol 253: E228-E231
7. Lönnroth P, Jansson P-A, Smith U (1988) Adipose tissue metabolism measured by microdialysis. In: Björntorp P, Rössner S (eds) Obesity in Europe 88. Libbey, London, pp 209-214

8. Andrée Larsen O, Lassen NA, Quaade F (1966) Blood flow through human adipose tissue determined with radioactive xenon. Acta Physiol Scand 66: 337-345

9. Crone C, Levitte DG (1984) Microcirculation. In: Renkin EM, Michel CC (eds) Handbook of Physiology, Vol 4. Am Physiological Society, Bethesda, pp 411-466

10. Del Prado S, Ferrannini E, DeFronzo RA (1987) Effect of insulin on the stoichiometry of glucose and lactate metabolism in the forearm. Diabetes 36 (Suppl 1): 41A (Abstract)

Received: 23 October 1989

and in revised form: 30 November 1989

Dr. U.Smith

Department of Medicine II

University of Gothenburg

Sahlgrens' Hospital

S-41345 Gothenburg

Sweden

\title{
Announcement
}

\author{
25th Anniversary Meeting of the European Association for the \\ Study of Diabetes
}

This meeting will be held from September 10-13, 1990, in the Bella Center, Copenhagen, Denmark. For further information please contact: EASD Secretariat, Auf'm Hennekamp 32, D-4000 Düsseldorf 1, FRG, or: EASD '90, c/o DIS Congress Service Copenhagen A/S, Linde Alle 48, DK-2720 Vanløse, Denmark. Tel.: + 4531712244 , Telex: 15476 dis dk, Telefax: + 4531716088 . 